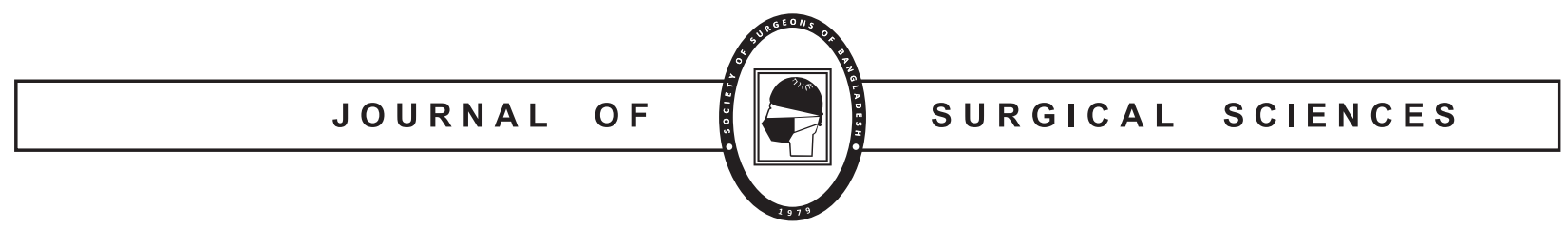

\title{
Editorial
}

\section{Guidance for surgical care during the COVID-19 pandemic}

\author{
Prof. AHM Shamsul Alam \\ Professor of Surgery (Retired), Bangladesh Medical College, Dhaka, Bangladesh,
}

The novel virus has come with its unfamiliar mode of transmission and disease potentials. Across the world all elective surgical procedures were suspended except emergency surgeries. Hospitals and country health services adopted immediate safety measures based on their understandings. After having relative ease of COVID-19 case load, hospitals are planning to start elective surgeries in a limited scale. However, there are uncertainties over several issues like risk of acquiring COVID-19 infection following elective surgery, fear of postoperative COVID-19 pneumonia, option of non-operative management for acute surgical conditions (e.g. antibiotic therapy for appendicitis), performing elective cancer surgery in hospitals affected by COVID-19 and quarantine of surgical team members to avoid the risk of infecting their family members, Having a guideline how to handle surgical cases and per surgical procedures has been a difficult task. There was an urgent need to coordinate the experiences of the countries across the world. To that end, there was a collaboration among USA, UK, Japan, India, china, Italy, Spain and Germany through COVIDSurg Collaborative and published a Global guidance for surgical care during the COVID-19 pandemic in British Journal of Surgery, March 2020. Following domains of surgical care were identified for planning and recommendations were suggested.

\begin{tabular}{ll}
\hline Domains & Recommendations \\
\hline $\begin{array}{l}\text { Prepare a pandemic response } \\
\text { plan forsurgical services }\end{array}$ & $\begin{array}{l}\text { All hospitals should prepare context-specific pandemic plans that can be } \\
\text { implemented as soonas COVID-19 cases are identified locally. Plans should } \\
\text { include all surgical specialties and bothelective and emergency services. }\end{array}$ \\
$\begin{array}{l}\text { Ensure staff are trained to } \\
\text { deliver surgerysafely during } \\
\text { pandemic }\end{array}$ & $\begin{array}{l}\text { Practice drills with experienced infection control teams, including: patient } \\
\text { transfers betweendifferent areas of the hospital; donning and doffing } \\
\text { personal protection equipment;recognizing and managing COVID-19 } \\
\text { infection. }\end{array}$ \\
$\begin{array}{l}\text { Support hospital response } \\
\text { to COVID-19 }\end{array}$ & $\begin{array}{l}\text { Reduce non-urgent activities, including outpatient clinics, endoscopy and } \\
\text { non-cancer electiveoperations. Plan how to continue delivering urgent } \\
\text { elective surgery safely, for example forpatients with cancer. }\end{array}$ \\
$\begin{array}{l}\text { Agree a team-based approach } \\
\text { for runningemergency services }\end{array}$ & $\begin{array}{l}\text { Antipate increased pressure on emergency surgical services during the } \\
\text { pandemic, with staffabsence owing to illness or quarantine. Establish team } \\
\text { structures that minimizecross-contamination and risk of nosocomial } \\
\text { infection. } \\
\text { Have a high index of suspicion for COVID-19 infection in both emergency } \\
\text { surgical admissionsand patients who develop postoperative respiratory } \\
\text { complications. Ensure there arearrangements in place for patients with. } \\
\text { COVID-19 infection }\end{array}$ \\
& suspected COVID-19 to be isolated and tested \\
\hline
\end{tabular}


There are general agreements as to the safety standards for surgical care. Surgical care recommendations are based on the experiences across the world. As the challenges are unfolding, medical professionals are changing their strategies constantly. However, the following guidelines could be helpful for us to take decisions in local settings.

\section{Outpatient clinics}

Outpatient clinic activity should be decreased to reduce the risk of cross-infection, particularly of elderly patients or those with co-morbidities. Online consultations need to be increased whenever feasible. Suspected or diagnosed patients with COVID-19 infection should be seen separately.

\section{Emergency surgical care}

Rapid testing for all emergency cases should be mandatory. Counseling should be done about possibility of contacting COVID-19 in hospital and an increase in morbidity, mortality and need for ICU care and before operative options should be considered keeping the patients under constant supervision. It is imperative to ensure that the patients do not get infected during transfer to operation theatre and other areas. Laparoscopic procedures should be abandoned.

\section{Elective surgery}

In the situation of severe outbreak, elective and day case surgeries should be withheld in order to make the resources of surgical disciplines available for COVID-19 affected patients and prevent further inhospital spread.

In a situation of limited outbreak, elective surgeries can be resumed based on certain criteria which include patients diagnosed as having malignant conditions and need surgery, patients with recurrent pain and possible deterioration if there is a delay, and surgeries that are unlikely to require ICU care.

\section{Operation theatre protocols}

Operation theatre should have adequate personal protective equipments (PPEs).

There should be separated donning and doffing areas, a dedicated changing areas and negative laminar airflow. Anesthetic circuit and equipments should be checked for possible leakage. Energy sources (eg diathermy) should be equipped with suction devices for smoke/aerosol control. Suction air/fluid must go through antiseptic liquids.

\section{Postoperative period}

Patients who develop fever of unknown origin or respiratory symptoms should be isolated, and chest CT performed or COVID-19 laboratory testing is to be considered. Such patients should be cared for by COVID-19-specific surgical teams if possible.

When planning patients' discharge, they should be given clear instructions to prevent contacting or transmitting COVID-19.

\section{Surgical team}

Surgical team members should be tested on regular basis. Staff sickness is likely in surgical teams and should be planned for, with surgeons preparing as teams rather than individually. Emergency scheduling and augmenting surgical teams with retired surgeons or final-year medical students to reduce pressure on working staff should be implemented. Consideration needs to be given to keeping the surgical workforce safe and able to complete their duties. Social distancing should be maintained by cancelling faceto-face meetings, and promoting teleconferencing, including that for multidisciplinary team meetings. Support should be identified for staff who have childcare needs, for example when schools are closed, or other caring responsibilities.

Consideration should be given to which staff members are at high risk of COVID-19 complications (such as pregnant surgeons, elderly surgeons, those with co-morbidities) and whether their duties should be altered to reduce the risk of infection. Based on the aforementioned guidance, hospitals should formulate own policy and implementation goals. An emergency COVID-19 pandemic task force can be formed to monitor the implementation of policies. As we are witnessing that new ideas and understandings are coming up on regular basis, need for communications and updates are essentials.

\section{Reference}

1. D. Nepogodiev, Global guidance for surgical care during the COVID-19 pandemic, Paper accepted 30 March 2020 Published online in Wiley Online Library (www.bjs.co.uk). DOI: 10.1002/bjs.11646 